\title{
( \pm )-Pestalachloride D, an Antibacterial Racemate of Chlorinated Benzophenone Derivative from a Soft Coral-Derived Fungus Pestalotiopsis sp.
}

\author{
Mei-Yan Wei ${ }^{1,2, \dagger}$, Dan $\mathrm{Li}^{1, \dagger}$, Chang-Lun Shao ${ }^{1, *}$, Dong-Sheng Deng ${ }^{3}$ and Chang-Yun Wang ${ }^{1, *}$ \\ 1 Key Laboratory of Marine Drugs, Ministry of Education, School of Medicine and Pharmacy, \\ Ocean University of China, Qingdao 266003, China; E-Mails: mywei95@126.com (M.-Y.W.); \\ lidaneasy@163.com (D.L.) \\ 2 School of Pharmacy, Guangdong Medical College, Dongguan 523808, China \\ 3 College of Chemistry and Chemical Engineering, Luoyang Normal University, Luoyang 471022 , \\ China; E-Mail: dengdongsheng168@sina.com
}

$\dagger$ These authors contributed equally to this work.

* Authors to whom correspondence should be addressed;

E-Mails: shaochanglun@163.com (C.-L.S.); changyun@ouc.edu.cn (C.-Y.W.);

Tel./Fax: +86-532-8203-1503 (C.-L.S.); +86-532-8203-1536 (C.-Y.W.).

Received: 17 February 2013; in revised form: 1 March 2013 / Accepted: 15 March 2013 /

Published: 28 March 2013

\begin{abstract}
A new antibacterial chlorinated benzophenone derivative, $( \pm)$-pestalachloride D (1), along with a related analog, $( \pm$ )-pestalachloride C (2), was recently isolated from the marine-derived fungus Pestalotiopsis sp. isolated from a soft coral Sarcophyton sp. collected from Yongxing Island in the South China Sea. Both chiral HPLC analysis and single-crystal $\mathrm{X}$-ray data indicated that $\mathbf{1}$ is a racemic mixture. Interestingly, $\mathbf{1}$ did not exhibit any effect in the zebrafish embryo teratogenicity assay, while $\mathbf{2}$ led to abnormal growth. The potential impact on zebrafish embryo growth is discussed based on their crystal structures. The main difference of crystal structures between $\mathbf{1}$ and $\mathbf{2}$ is that the six-member non-aromatic ring $\left(\mathrm{O} 4, \mathrm{C} 10, \mathrm{C} 9, \mathrm{C} 8, \mathrm{C} 2^{\prime}\right.$, and C3') in $\mathbf{1}$ exhibits a distorted chair conformation, while $\mathbf{2}$ shows a distorted boat conformation. Moreover, compounds $\mathbf{1}$ and $\mathbf{2}$ both exhibited moderate antibacterial activity.
\end{abstract}

Keywords: $( \pm)$-pestalachloride D; antibacterial activity; zebrafish embryo teratogenicity assay; marine-derived fungus; Pestalotiopsis sp.; single-crystal X-ray 


\section{Introduction}

Over the past two decades, marine-derived fungi have proven to be rich sources of structurally novel and biologically active secondary metabolites, which have become significant resources for drug discovery [1,2]. Furthermore, a growing body of evidence indicates that the genus Pestalotiopsis represents a huge and largely untapped resource of natural products with chemical structures that have been optimized by evolution for biological and ecological importance [3]. During the past two decades, about 200 fungal secondary metabolites including terpenoids, alkaloids, lactones, and coumarins, have been reported from this genus [3].

Chemically-induced teratogenicity is preventable with proactive reproductive safety evaluations. The developing zebrafish (Danio rerio) is an in vivo developmental model with a number of advantages over in vitro systems and provides a simple, inexpensive and rapid assay to screen for teratogenicity [4,5]. As part of our ongoing investigation into new natural metabolites, a series of antibacterial, antifouling and cytotoxic products have been isolated from marine fungi from the South China Sea [6-9]. Under the guidance of zebrafish embryo teratogenicity assay, a new chlorinated benzophenone derivative, $( \pm$ )-pestalachloride D (1), along with one related known analogue, ( \pm )-pestalachloride C (2) [10] (Figure 1), was obtained from the organic extracts of the marine-derived fungus Pestalotiopsis sp. The fungus was isolated from a soft coral Sarcophyton sp. collected from Yongxing Island in the South China Sea. Both 1 and $\mathbf{2}$ are dichlorinated and were found to be racemic mixtures by chiral HPLC analysis and single-crystal X-ray data.

Figure 1. Structures of compounds 1 and 2.
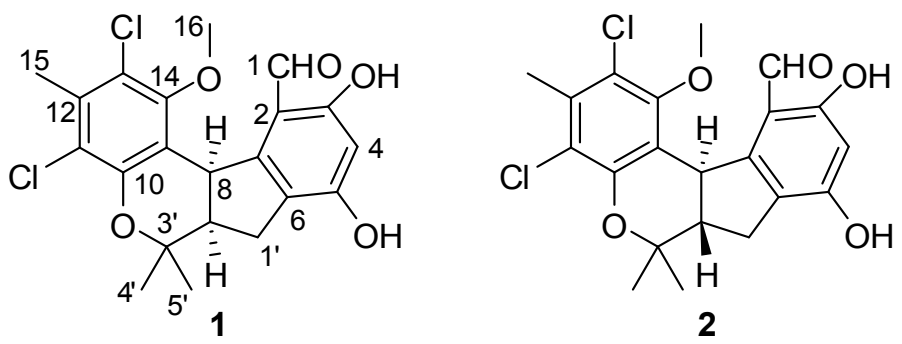

Herein, we report the isolation, structure determination, chiral HPLC analysis, antibacterial activity and zebrafish embryo teratogenicity effect for the racemic mixtures. The potential impact on zebrafish embryo growth is also discussed based on the crystal structures.

\section{Results and Discussion}

The marine-derived fungus ZJ-2009-7-6, isolated from the soft coral Sarcophyton sp., was identified by molecular characteristics along with morphologic traits as a Pestalotiopsis sp. Both $( \pm$ )-pestalachloride D (1) and ( \pm )-pestalachloride C (2) were isolated using chromatographic techniques, including column chromatography and semi-preparative HPLC, and their structures were elucidated by comprehensive spectroscopic data (IR, UV and NMR), along with HREIMS and X-ray diffraction analyses.

Compound 1 was obtained as colorless crystals. The HREIMS data $(\mathrm{m} / \mathrm{z} 422.0678$, calcd 422.0682) together with its ${ }^{13} \mathrm{C}$ NMR spectrum indicated that it has a molecular formula of $\mathrm{C}_{21} \mathrm{H}_{20} \mathrm{Cl}_{2} \mathrm{O}_{5}$ with 
11 degrees of unsaturation. Furthermore, the ratio of $[\mathrm{M}]^{\circ+}$ isotopic peaks (422:424:426/10:6:1) clearly indicated the presence of two chlorine atoms. The ${ }^{13} \mathrm{C}$ NMR and DEPT spectra revealed 21 carbon signals, including one appearing to be an aldehyde group $\left(\delta_{C} 193.4\right)$ and twelve aromatic carbons, representing two phenyl rings. With nine of the 11 degrees of unsaturation accounted for, the structure of 1 was suggested to contain another two rings. The IR absorption bands at 3444 and $1647 \mathrm{~cm}^{-1}$ suggested the presence of both a hydroxyl and carbonyl groups. Careful comparison of the ${ }^{1} \mathrm{H} N M R$ and ${ }^{13} \mathrm{C}$ NMR data of 1 (Table 1) with those of ( \pm )-pestalachloride $C(2)$, which was previously reported from the plant endophytic fungus Pestalotiopsis adusta (L416) [10], showed close structural homology to 2 . The most obvious differences involved coupling constants. In 1, a small coupling constant $(J=6.0 \mathrm{~Hz})$ was observed between $\mathrm{H}-8\left(\delta_{\mathrm{H}} 4.71\right)$ and $\mathrm{H}-2^{\prime}\left(\delta_{\mathrm{H}} 2.81\right)$, instead of a large coupling constant observed $(J=11.2 \mathrm{~Hz})$ between $\mathrm{H}-8\left(\delta_{\mathrm{H}} 4.26\right)$ and $\mathrm{H}-2^{\prime}\left(\delta_{\mathrm{H}} 2.30\right)$ in 2 . This small coupling constant between $\mathrm{H}-8$ and $\mathrm{H}-2^{\prime}$ indicated a cis-relationship between these protons, where as in $\mathbf{2}$ it has been reported to have a trans-related. Finally, by slow crystallization from $\mathrm{MeOH}$, single crystals of 1 suitable for X-ray diffraction analysis using $\mathrm{Cu} K \alpha$ radiation were obtained, allowing the structure of $\mathbf{1}$ to be unambiguously established with H-8 and H-2' in a cis relationship (Figure 2). Single crystals of 2 were also obtained and measured. According to the crystal data of $\mathbf{1}$ and $\mathbf{2}$, the dihedral angles between H-8 and $\mathrm{H}-2^{\prime}$ were calculated to be $c a .35^{\circ}$ and $159^{\circ}$, respectively, which were consistent with the values deduced by the Karplus formula. The planar and relative structure of $\mathbf{1}$ was completely determined as shown in Figure 2.

Table 1. ${ }^{1} \mathrm{H}$ and ${ }^{13} \mathrm{C}$ NMR Data for $\mathbf{1}^{\mathrm{a}}$.

\begin{tabular}{|c|c|c|}
\hline \multirow{2}{*}{ Position } & \multicolumn{2}{|r|}{1} \\
\hline & $\boldsymbol{\delta}_{\mathrm{C}}$ & $\delta_{\mathrm{H}}(\mathrm{J} / \mathrm{Hz})$ \\
\hline 1 & 193.4 & $10.21(1 \mathrm{H}, \mathrm{s})$ \\
\hline 2 & 112.9 & \\
\hline 3 & 163.6 & \\
\hline 4 & 102.1 & $6.20(1 \mathrm{H}, \mathrm{s})$ \\
\hline 5 & 158.5 & \\
\hline 6 & 120.0 & \\
\hline 7 & 148.5 & \\
\hline 8 & 38.7 & $4.71(1 \mathrm{H}, \mathrm{d}, 6.0)$ \\
\hline 9 & 121.4 & \\
\hline 10 & 150.0 & \\
\hline 11 & 114.0 & \\
\hline 12 & 135.6 & \\
\hline 13 & 119.4 & \\
\hline 14 & 154.0 & \\
\hline 15 & 17.9 & $2.42(3 \mathrm{H}, \mathrm{s})$ \\
\hline 16 & 60.2 & $3.59(3 \mathrm{H}, \mathrm{s})$ \\
\hline $1^{\prime}$ & 27.5 & $2.81(2 \mathrm{H}$, overlapped $)$ \\
\hline $2^{\prime}$ & 51.1 & $2.81(1 \mathrm{H}$, overlapped $)$ \\
\hline $3^{\prime}$ & 75.6 & \\
\hline $4^{\prime}$ & 26.8 & $1.55(3 \mathrm{H}, \mathrm{s})$ \\
\hline $5^{\prime}$ & 24.6 & $1.38(3 \mathrm{H}, \mathrm{s})$ \\
\hline $\mathrm{OH}-3$ & & 11.74, brs \\
\hline
\end{tabular}


Figure 2. Perspective ORTEP drawing for 1.

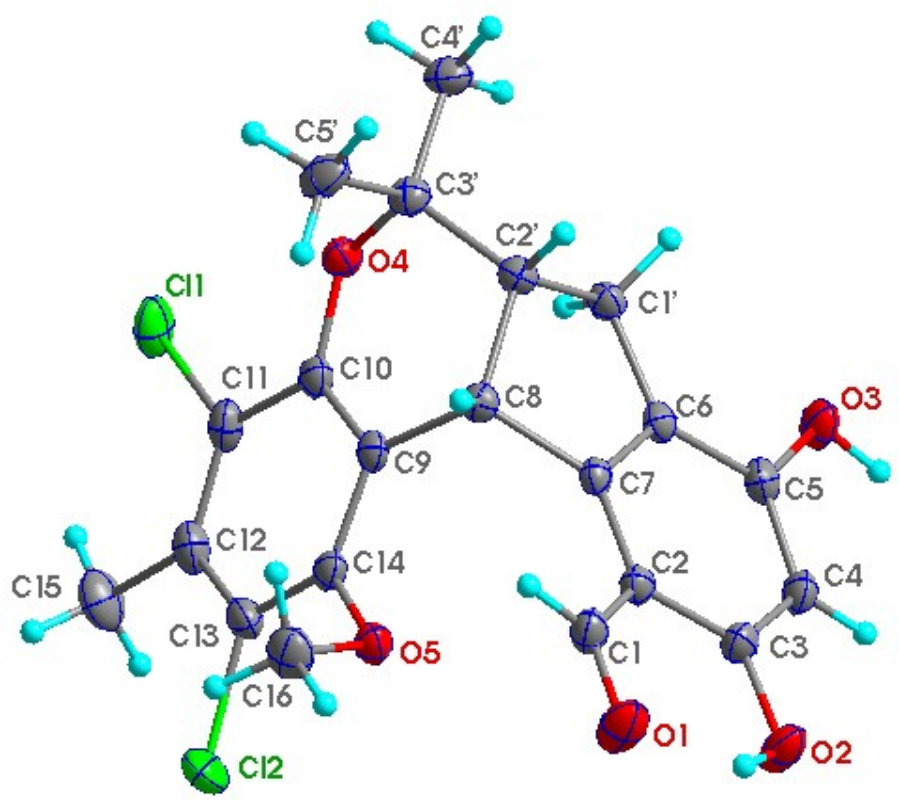

The space group $P 2_{1} / \mathrm{c}$ of the crystallographic data indicated 1 is a racemate with $S S / R R$ configurations. The specific rotation $[\alpha]_{\mathrm{D}}^{25} 0\left(c 1.00, \mathrm{CHCl}_{3}\right)$ and the absence of a CD maximum also confirmed the above result. This was further supported by subsequent HPLC analysis of $( \pm)-\mathbf{1}$ on a chiral phase column, in which two distinct chromatographic peaks appeared with a ratio of $1: 1$. In fact, several natural products including ( \pm )-pestalachloride C [10], sporothrins A and B [11], and longamide [12] have also been found as racemic mixtures.

A possible biogenetic pathway of $( \pm)$-pestalachlorides $\mathrm{D}(\mathbf{1})$ and $\mathrm{C}(\mathbf{2})$ is proposed as shown in Scheme 1. The dichloro-substituted phenol (A) is firstly deprotonated, and resonanized to a stabilized carbanion (B). Then the resulting carbanion undergoes an Aldol reaction by attacking the carbonyl group of the aldehyde $(\mathrm{C})$ to generate a tetrahedral intermediate followed by capturing a proton to form a secondary alcohol (D). The resulting alcohol dehydrates to an $\alpha, \beta$-unsaturated ketone (E), then undergoes an intramolecular [4 2] hetero-Diels-Alder reaction to afford the product, $( \pm)$-pestalachloride D (1) and ( \pm )-pestalachloride $C(2)$. This deduction was supported by the co-isolation of the intermediate metabolite, pestalone (3), which was isolated from the plant endophytic fungus Pestalotiopsis adusta (L416) [10]. Interestingly, a novel meroterpenoid, $( \pm$ )-Guajadial B, was recently isolated from Psidium guajava and also synthesized by biomimetic strategy which also contains a hetero-Diels Alder reaction [13].

All the biological activities of compounds $\mathbf{1}$ and $\mathbf{2}$ were evaluated as their racemic forms. Compounds 1 and 2 were evaluated in the zebrafish (D. rerio) embryo teratogenicity assay. To our surprise, compound 1 was inactive at a concentration of $50 \mu \mathrm{g} / \mathrm{mL}$, while 2 led to abnormal growth effects in several aspects of the embryonic development. For example, 2 exhibited coagulated eggs $(24 \mathrm{~h})$, non-spontaneous movements $(24 \mathrm{~h})$, abnormal heartbeat $(48 \mathrm{~h})$, tail malformation $(48 \mathrm{~h})$, heart malformation (48 h), notochord malformation (72 h), delayed hatch (72 h) and embryo death (72 h) with $\mathrm{EC}_{50}$ values of $16.3,18.6,6.3,24.5,8.2,5.8,7.4$ and $12.6 \mu \mathrm{g} / \mathrm{mL}$, respectively. These results indicate that the trans relative configuration between $\mathrm{H}-8$ and $\mathrm{H}-2^{\prime}$ in 2 potentially contributes to the toxic effects of 2 . 
Scheme 1. Possible biogenetic path of $( \pm)$-pestalachlorides D (1) and C (2).

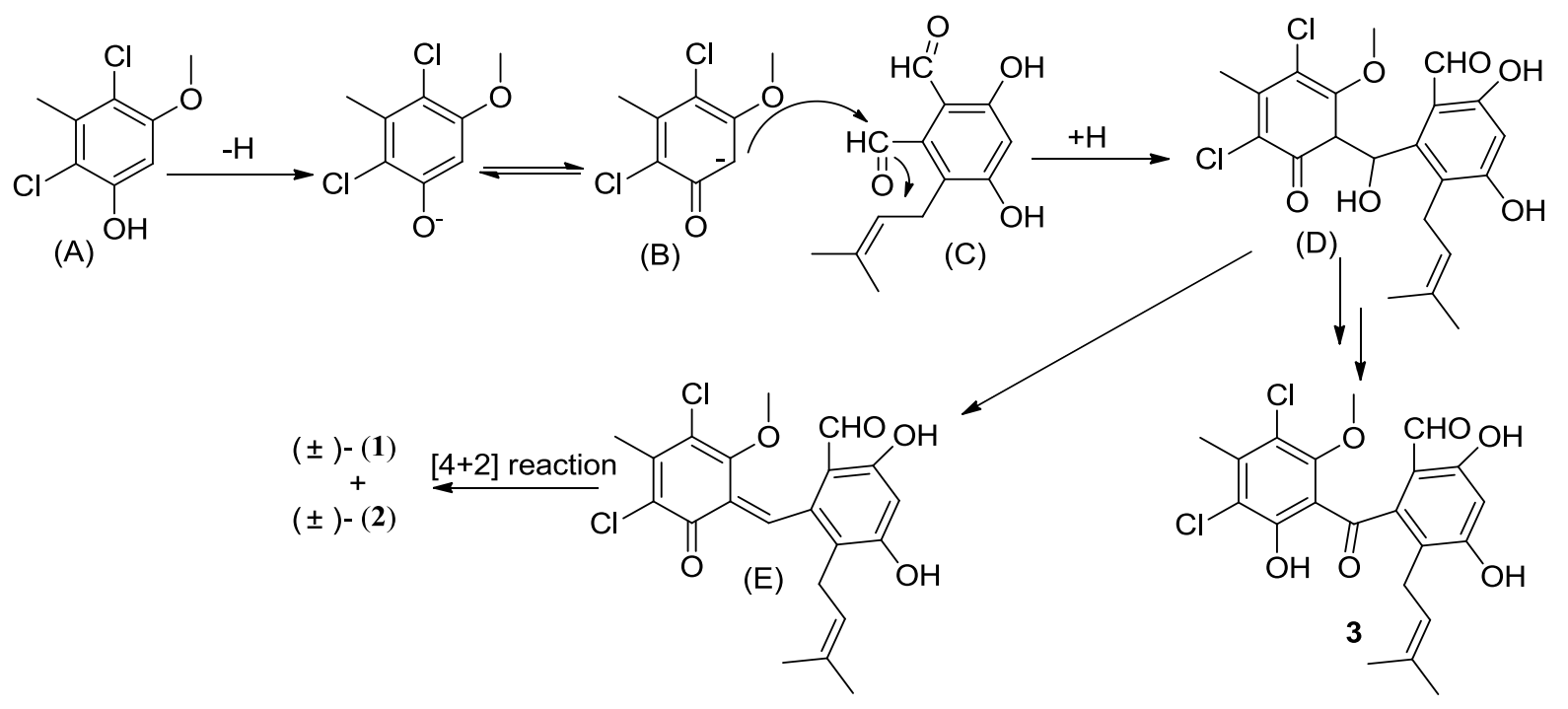

In order to explain the possible conformational differences and their effects on toxicity, we focus on the two crystal structures. Here are some obvious conformational differences of two non-benzene rings. Firstly, the crystal of compound $\mathbf{1}$ is monoclinic system with space group $P 2_{1} / \mathrm{c}$, and crystal of $\mathbf{2}$ is triclinic system in space group $P \overline{\mathbf{1}}$. Secondly, in the crystal of $\mathbf{1}$, one six-member non-aromatic ring (O4, C10, C9, C8, C2', and C3') exhibits a distorted chair conformation with atoms $\mathrm{O} 4$ and $\mathrm{C} 8$ deviating by $0.405(4)$ and $-0.352(4) \AA$, respectively, from the mean plane of the other four atoms (Figure 3 ). Correspondingly, in the crystal of $\mathbf{2}$, the non-aromatic six-membered ring showing a distorted boat conformation is anti-fused along the $\mathrm{C} 8-\mathrm{C} 2$ ' bond to a five-membered ring, placing the atoms $\mathrm{O} 4$ and $\mathrm{C} 8$ on the prow and stern positions deviating by $0.376(3)$ and $0.778(3) \AA$, respectively, from the mean plane of the other four atoms (Figure 4). Thirdly, in compound 1, the five-membered ring (C7, C6, C1', $\mathrm{C} 2$ ' and $\mathrm{C} 8$ ) with a cis-junction to the six-membered non-aromatic ring along the $\mathrm{C} 8-\mathrm{C} 2$ ' bond adopts a envelope conformation with $\mathrm{C} 2$ ' away from the mean plane of the other four atoms by $-0.489(3) \AA$. It should be noted that the tetracyclic skeleton of $\mathbf{1}$ exists predominantly in a "butterfly" conformation, in which the dihedral angle between the two wings formed by two aromatic rings is about $82.8(5)^{\circ}$. This arrangement makes the methoxy group tilt out of the corresponding aromatic ring (dichlorophene) by $79.5^{\circ}$, appearing on the $\alpha$-face of the molecule (Figure 5). However, in compound 2 , the five-membered ring (C6, $\mathrm{C} 7, \mathrm{C} 8, \mathrm{C} 2^{\prime}$, and $\left.\mathrm{C} 1^{\prime}\right)$ displays an envelope conformation with $\mathrm{C} 2$ ' deviating out of the mean plane of the other four atoms by -0.427 (3) $\AA$. It must be pointed out that the structural landscape of 2 exhibits a "butterfly" conformation, in which two wings constructed by two aromatic rings form the dihedral angles of $51.4(3)^{\circ}$. Furthermore, the methoxy group deviates out of the dichlorophene about $89.9^{\circ}$. Within this mode, the methoxy group and methyl group $\left(\mathrm{C}^{\prime}\right)$ are projected on $\beta$-face of the molecule (Figure 6). These above configurational differences could partly explain why the two compounds have so obviously different effects on the embryonic development of the zebrafish. Further studies on the effect mechanisms are in progress. 
Figure 3. The distorted half-chair conformation of six-membered non-aromatic ring $\left(\mathrm{C} 8, \mathrm{C} 9, \mathrm{C} 10, \mathrm{O} 4, \mathrm{C} 3{ }^{\prime}, \mathrm{C} 2{ }^{\prime}\right)$ in $\mathbf{1}$.

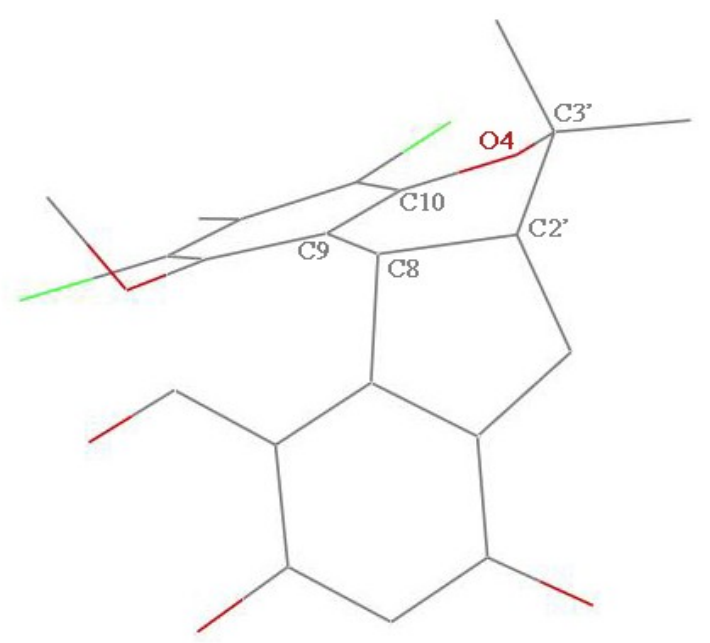

Figure 4. The distorted boat conformation of six-membered non-aromatic ring $\left(\mathrm{C} 8, \mathrm{C} 9, \mathrm{C} 10, \mathrm{O} 4, \mathrm{C} 3{ }^{\prime}, \mathrm{C} 2{ }^{\prime}\right)$ in 2.

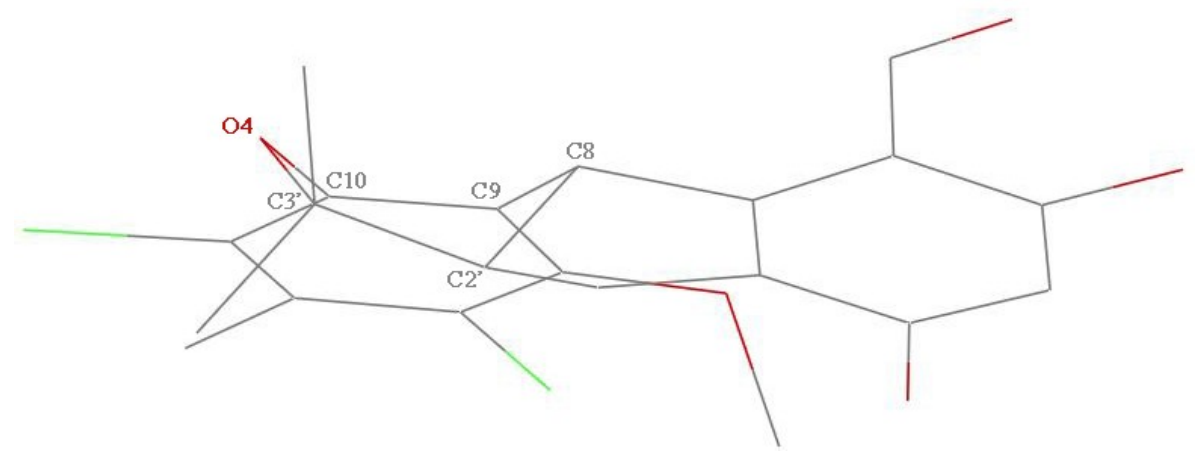

Figure 5. The "butterfly" conformation of $\mathbf{1}$.

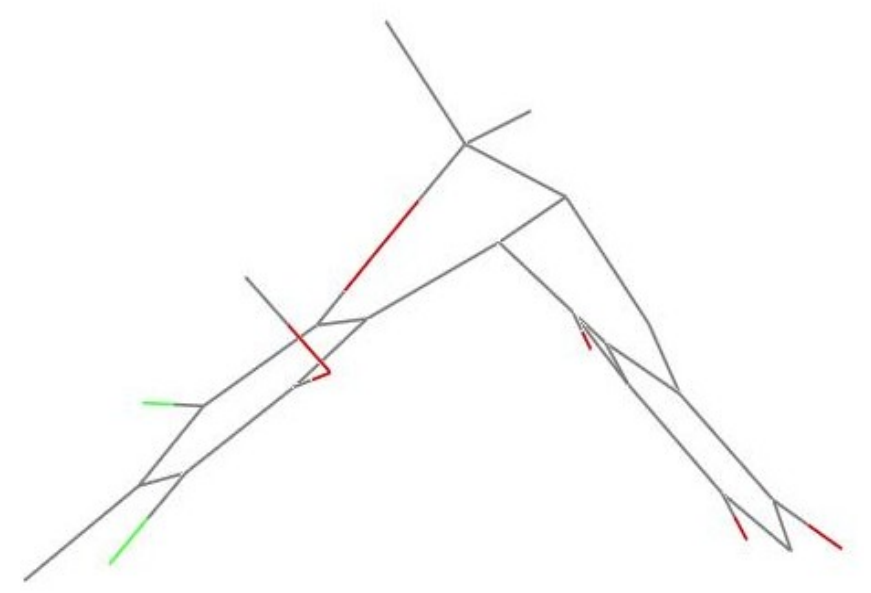


Figure 6. The "butterfly" conformation of 2.

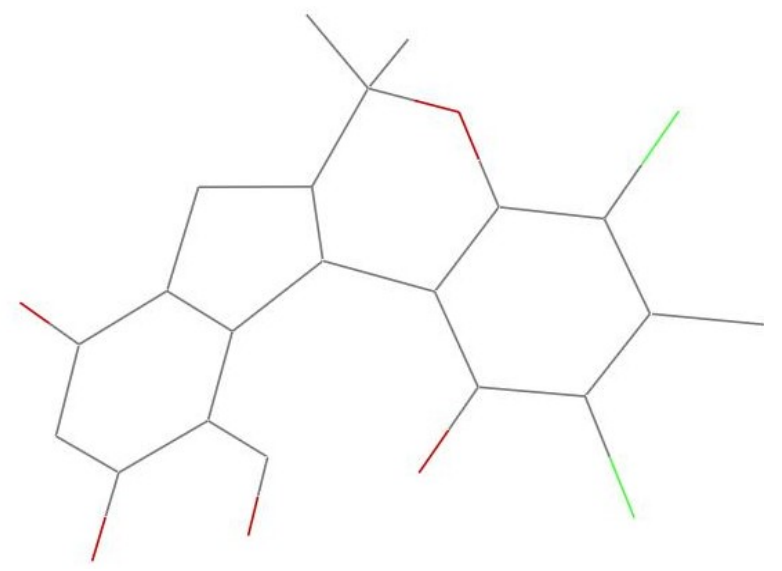

Compounds $\mathbf{1}$ and $\mathbf{2}$ both exhibited moderate antibacterial activity against Escherichia coli, Vibrio anguillarum and Vibrio parahaemolyticus with the MIC values of 5.0, 10.0 and $20.0 \mu \mathrm{M}$, respectively. Neither of them showed any inhibitory activity against Micrococcus tetragenus at a concentration of $20.0 \mu \mathrm{M}$.

Moreover, $\mathbf{1}$ and $\mathbf{2}$ did not show any herbicidal activity against Arabidopsis thaliana at 10 ppm and Poa апnиa at $32 \mathrm{ppm}$. Nor did they exhibit any insecticidal activity against Plutella xylostella and Diabrotica balteata at $500 \mathrm{ppm}$ in artificial diet assays, and the mycelial growth tests in artificial media against Pythium dissimile, Alternaria solani, Botryotinia fuckeliana and Gibberella zeae at rates of 20 and 2 ppm.

\section{Experimental Section}

\subsection{General Experimental Procedures}

Melting points were determined on an X-6 micromelting point apparatus and are uncorrected. Optical rotations were measured on a JASCO P-1020 digital polarimeter. UV spectra were recorded on an UV-2501PC spectrophotometer. IR spectra were recorded on a Bruker EQUINOX 55 spectrometer using $\mathrm{KBr}$ pellets. NMR spectra were recorded on a JEOL JEM-ECP NMR spectrometer (600 MHz for ${ }^{1} \mathrm{H}$ and $150 \mathrm{MHz}$ for ${ }^{13} \mathrm{C}$ ) and on a Bruker AVANCE $400 \mathrm{NMR}$ spectrometer $\left(400 \mathrm{MHz}\right.$ for ${ }^{1} \mathrm{H}$ and $100 \mathrm{MHz}$ for ${ }^{13} \mathrm{C}$ ). Chemical shifts $\delta$ are reported in ppm, using TMS as internal standard and coupling constants $(J)$ are in Hz. EIMS spectra were measured on a Thermo DSQ EI-mass spectrometer and HREIMS on a Thermo MAT95XP High Resolution mass spectrometer. Single-crystal data was measured on an Agilent Gemini ultra diffractometer ( $\mathrm{Cu} \mathrm{K} \alpha$ radiation). HPLC separation was performed in a Waters 1525 preparative HPLC system coupled with Waters 2996 photodiode array detector. A Kromasil $\mathrm{C}_{18}$ preparative HPLC column $(250 \mathrm{~mm} \times 10 \mathrm{~mm}, 5 \mu \mathrm{m})$ and a chiral Crownpak CR $(+)$ column $(150 \mathrm{~mm} \times 4 \mathrm{~mm}, 5 \mu \mathrm{m})$ were used. Silica gel (Qing Dao Hai Yang Chemical Group Co.; 200-300 mesh), octadecylsilyl silica gel (Unicorn; 45-60 $\mu \mathrm{m}$ ) and Sephadex LH-20 (GE Healthcare, Bio-Science AB, Sweden) were used for column chromatography (CC). Precoated silica gel plates (Yan Tai Zi Fu Chemical Group Co.; G60, F-254) were used for thin layer chromatography (TLC). The antibacterial activities were observed with a Multiskan Mk3 (Thermo Labsystems) at $630 \mathrm{~nm}$. A vertical heating pressure steam sterilizer LDZX-75KBS was used for the sterilization of culture medium. The 
fungi were cultivated in a Biochemical Incubator (Model SPX-250B-Z) or SHIPING Constant Temperature Culture Vibrator at $25^{\circ} \mathrm{C}$ with a speed of $160 \mathrm{rpm}$.

\subsection{Isolation of the Fungal Material}

The fungal strain Pestalotiopsis sp. (ZJ-2009-7-6) was isolated from a piece of fresh tissue from the inner part of a soft coral Sarcophyton sp., collected from Yongxing Island in the South China Sea in November, 2009. The strain was deposited at the Key Laboratory of Marine Drugs, the Ministry of Education of China, School of Medicine and Pharmacy, Ocean University of China, Qingdao, China. Following surface sterilization with $75 \% \mathrm{EtOH}$ for $30 \mathrm{~s}$, the soft coral was rinsed three times in sterile water. To distinguish the remaining epiphytic fungi from endophytic fungi, an imprint of the soft coral surface on PDA was made. Small tissue samples from inner part of the soft coral were aseptically cut and pressed onto PDA plates containing an antibiotic to suppress bacterial growth (composition of isolation medium: $200 \mathrm{~g} / \mathrm{L}$ potatoes, glucose $20 \mathrm{~g} / \mathrm{L}$, agar $15 \mathrm{~g} / \mathrm{L}$, and chloramphenicol $0.2 \mathrm{~g} / \mathrm{L}$ in sea water, $\mathrm{pH}$ 7.4-7.8). After incubation at $25{ }^{\circ} \mathrm{C}$, the fungal strain under investigation was found to grow exclusively out of the soft coral tissue, but not on the agar plates taken from the imprint of the soft coral surface. A pure strain of Pestalotiopsis sp. (ZJ-2009-7-6) was isolated from the growing cultures by repeated re-inoculation on PDA plates.

\subsection{Identification of Fungal Cultures}

The fungus was identified as Pestalotiopsis sp. according to morphologic traits and a molecular biological protocol by DNA amplification and sequencing as described below. About $100 \mathrm{mg}$ of fresh fungal mycelium was collected in a microcentrifuge tube $(1.5 \mathrm{~mL})$ to extract genomic DNA from the fungus using the Fungal DNA Kit (50) (E.Z.N.A., Omega) according to the manufacturer's protocol. The PCR reactions were performed in a final volume of $50 \mu \mathrm{L}$ which was composed of template DNA $(2 \mu \mathrm{L}), 5 \mu \mathrm{L} 10 \times$ buffer, $1 \mu \mathrm{L}$ dNTP, $0.5 \mu \mathrm{L}$ ITS1F, $0.5 \mu \mathrm{L}$ ITS4 $(20 \mu \mathrm{mol} / \mathrm{mL}$ each $), 0.25 \mu \mathrm{L}$ of Taq polymerase and appropriate ultrapure water under the following conditions: (1) initial denaturation at $94{ }^{\circ} \mathrm{C}$ for $5 \mathrm{~min}$; (2) denaturation at $94{ }^{\circ} \mathrm{C}$ for $40 \mathrm{~s}$; (3) annealing at $52{ }^{\circ} \mathrm{C}$ for $40 \mathrm{~s}$; (4) extension at $72{ }^{\circ} \mathrm{C}$ for $1 \mathrm{~min}$; (5) final extension at $72{ }^{\circ} \mathrm{C}$ for $10 \mathrm{~min}$. Steps $2-4$ were repeated 30 times. Then, $5 \mu \mathrm{L}$ of the amplification products was loaded onto an agarose gel $(1.2 \%$ agarose in $0.5 \times \mathrm{TAE}, 5 \mu \mathrm{L}$ of ethidium bromide $1 \% \mathrm{~m} / \mathrm{v}$ solution per $100 \mathrm{~mL}$ of gel). After electrophoresis at $100 \mathrm{~V}$ for $35 \mathrm{~min}$, the band due to the PCR product (approximate size $526 \mathrm{bp}$ ) was isolated from the gel slice using the Gel Extraction Kit (E.Z.N.A., Omega) according to the manufacturer's protocol. The PCR product was then submitted for sequencing (Invitrogen, Shanghai) with the primer ITS4. The fungus was identified as a Pestalotiopsis sp. whose 617 base pair ITS sequence had 99\% sequence identity to that of Pestalotiopsis sp. DFFW (EF055190). The sequence data have been submitted to GenBank, accession number HM486429.

\subsection{Fermentation, Extraction and Isolation}

The fungal strain Pestalotiopsis sp. (ZJ-2009-7-6) was cultivated in 20 L liquid medium (composition of medium: $200 \mathrm{~g} / \mathrm{L}$ cooked and sliced potatoes, $20 \mathrm{~g} / \mathrm{L}$ glucose in artificial sea water, in $1 \mathrm{~L}$ Erlenmeyer flasks each containing $400 \mathrm{~mL}$ of culture broth) at $27^{\circ} \mathrm{C}$ without shaking for 4 weeks. The culture was 
filtered to separate the culture broth from the mycelia. Then the fungal mycelia were extracted three times with EtOAc and three times with $\mathrm{CHCl}_{3} / \mathrm{MeOH}(\mathrm{v} / \mathrm{v}, 1: 1)$. The organic extracts were combined and concentrated under vacuum to afford a dry crude extract $(6.2 \mathrm{~g})$. The resulting exact (6.2 g) was subjected to silica gel column chromatography $(\mathrm{CC})$ (petroleum ether, EtOAc v/v, gradient elution) to offer seven fractions (Fr. 1-Fr. 7). Fr. 3 was subjected to silica gel CC with petroleum ether-EtOAc (4:1) and Sepphadex LH-20 CC eluting with mixtures of petroleum ether- $\mathrm{CHCl}_{3}-\mathrm{MeOH}$ (2:1:1). Further purification by semi-preparative HPLC using a C18 column eluting with $90 \%$ of $\mathrm{MeOH} / \mathrm{H}_{2} \mathrm{O}$ at a flow rate of $2.0 \mathrm{~mL} / \mathrm{min}$ yielded compounds $\mathbf{1}(5.0 \mathrm{mg})$ and $\mathbf{2}(18.0 \mathrm{mg})$.

( \pm )-Pestalachloride D (1): colorless crystals; mp 225-227 ${ }^{\circ} \mathrm{C} ;[\alpha]^{25}{ }_{\mathrm{D}}=0$ (c $\left.1.00, \mathrm{CHCl}_{3}\right)$; UV $\lambda_{\max }(\mathrm{MeOH}) \mathrm{nm}: 209$ (3.53), 283 (3.26), 327 (3.08) nm; IR (KBr) $v_{\max }$ 3444, 1647, 1558, 1450, 1379, 1271, $1149 \mathrm{~cm}^{-1} ;{ }^{1} \mathrm{H}$ NMR and ${ }^{13} \mathrm{C}$ NMR, see Table 1; EIMS $\mathrm{m} / z 422[\mathrm{M}]^{++}$; HREIMS $\mathrm{m} / z$ $422.0678[\mathrm{M}]^{\cdot+}$ (calcd for $\mathrm{C}_{21} \mathrm{H}_{20} \mathrm{Cl}_{2} \mathrm{O}_{5}, 422.0682$ ).

X-ray Crystallographic Analysis of $\mathbf{1}$ and 2. Colorless crystals of $\mathbf{1}$ and $\mathbf{2}$ were both obtained from $\mathrm{MeOH}$. The crystal data were recorded at $293 \mathrm{~K}$ on an Agilent Gemini ultra diffractometer with $\mathrm{Cu} \mathrm{K \alpha}$ radiation $(\lambda=1.54718 \AA)$ and Mo Ka radiation $(\lambda=0.71073 \AA)$. Their structures were solved by direct methods (SHELXS-97) and refined using full-matrix least-squares difference Fourier techniques. All non-hydrogen atoms were refined anisotropically, and all hydrogen atoms were placed in idealized positions and refined as riding atoms with the relative isotropic parameters. The crystallographic data for $\mathbf{1}$ and $\mathbf{2}$ have been deposited at the Cambridge Crystallographic Data Centre with the deposition numbers 896,051 and 896,954, respectively. Copies of the data can be obtained, free of charge, on application to the Director, CCDC, 12 Union Road, Cambridge CB21EZ, UK (Fax: +44(0)-1233-336033 or E-Mail: deposit@ccdc.cam.ac.uk).

Crystal data for $1: \mathrm{C}_{21} \mathrm{H}_{20} \mathrm{Cl}_{2} \mathrm{O}_{5}, \mathrm{Mr}=423.27$, monoclinic, space group $P 2{ }_{1} / \mathrm{c}$ with $a=18.4179(4) \AA$, $b=9.2808(2) \AA, c=11.3163(3) \AA, \alpha=\gamma=90^{\circ}, \beta=91.466(2)^{\circ}, V=1933.69(8) \AA^{3}, Z=4$, $D x=1.454 \mathrm{mg} / \mathrm{m}^{3}, \mu(\mathrm{Cu} \mathrm{K \alpha})=3.289 \mathrm{~mm}^{-1}$, and $F(000)=880$. Crystal dimensions: $0.42 \times 0.41 \times 0.31 \mathrm{~mm}^{3}$. Independent reflections: $2765\left(R_{\text {int }}=0.0334\right)$. The final $R_{1}$ values were 0.0341 , $\mathrm{wR} 2=0.0891(I>2 \sigma(I))$.

Crystal data for 2: $\mathrm{C}_{22} \mathrm{H}_{24} \mathrm{Cl}_{2} \mathrm{O}_{6}, \mathrm{Mr}=455.31$, Triclinic, space group $P-1$ with $a=9.0363(18) \AA$, $b=10.083(2) \AA, c=12.356(2) \AA, \alpha=68.534(3)^{\circ}, \beta=82.589(3)^{\circ}, \gamma=87.258(3), V=1039.0(4) \AA^{3}$, $Z=2, D x=1.455 \mathrm{mg} / \mathrm{m}^{3}, \mu(\mathrm{Mo} \mathrm{K} \alpha)=0.350 \mathrm{~mm}^{-1}$, and $F(000)=476$. Crystal dimensions: $0.43 \times 0.31 \times 0.17 \mathrm{~mm}^{3}$. Independent reflections: $3984\left(R_{\text {int }}=0.0299\right)$. The final $R_{1}$ values were 0.0476 , $\mathrm{wR} 2=0.1329(I>2 \sigma(I))$.

\subsection{Biological Assays}

The antibacterial activities against four bacterial strains, Gram-positive M. tetragenus (ATCC 13623), Gram-negative E. coli (ATCC 25922), V. anguillarum (ATCC 19019) and V. parahaemolyticus (ATCC 17802) were determined by a serial dilution technique using 96-well microtiter plates [14]. The compounds were dissolved in DMSO to give a stock solution. Bacterial species were cultured overnight at $37{ }^{\circ} \mathrm{C}$ in LB broth and diluted to $10^{6} \mathrm{cfu} / \mathrm{mL}$ when used. LB broth was used as a blank control, and DMSO was used as a negative control, while ciprofloxacin was used as a positive control. 
The plates were incubated at $37{ }^{\circ} \mathrm{C}$ for $24 \mathrm{~h}$. The results were observed with a Multiskan Mk3 (Thermo Labsystems) at $630 \mathrm{~nm}$. The zebrafish embryo teratogenicity assays were evaluated according to the described methods [4,5]. The agrochemical assays were evaluated by the methods described previously [15].

\section{Conclusions}

In summary, one new chlorinated benzophenone derivative, $( \pm)$-pestalachloride $\mathrm{D}(\mathbf{1})$, and its epimer ( \pm )-pestalachloride C (2), have been isolated from a soft coral-derived fungus Pestalotiopsis sp. The structure of the new metabolite (1) was identified by comprehensive spectroscopic data. Both chiral HPLC analysis and single-crystal X-ray data indicated that $\mathbf{1}$ is a racemic mixture. Compound $\mathbf{2}$ exhibited toxicity toward zebrafish embryo, while $\mathbf{1}$ was completely inactive, and this is potentially due to the configurational differences observed in their crystal structures. This work will help to further understand the potential effect mechanisms of the zebrafish embryo teratogenicity assays. Furthermore, the separation of the enantiomers and further biological evaluation of the optically pure compounds are still in progress.

\section{Acknowledgments}

Chang-Lun Shao appreciates the useful discussion with William H. Gerwick group (SIO, UCSD), especially Emily Mevers and thanks Syngenta for the agrochemical assays. We acknowledge funding from the Program of National Natural Science Foundation of China (NSFC) (Nos. 41130858, 81172977 and 41176121), the Natural Science Foundation of Shandong Province (No. ZR2011DQ019) and the Program for New Century Excellent Talents in University, Ministry of Education of China grant to Chang-Lun Shao (No. NCET-11-0472).

\section{Conflict of Interest}

The authors declare no conflict of interest.

\section{References}

1. Blunt, J.W.; Copp, B.R.; Keyzers, R.A.; Munro, M.H.G.; Prinsep, M.R. Marine natural products. Nat. Prod. Rep. 2012, 29, 144-222.

2. Newman, D.J.; Cragg, G.M. Natural products as sources of new drugs over the 30 years from 1981 to 2010. J. Nat. Prod. 2012, 75, 311-335.

3. Yang, X.-L.; Zhang, J.-Z.; Luo, D.-Q. The taxonomy, biology and chemistry of the fungal Pestalotiopsis genus. Nat. Prod. Rep. 2012, 29, 622-641.

4. Parng, C.; Seng, W.L.; Semino, C.; McGrath, P. A preclinical model for drug screening. Assay Drug Dev. Technol. 2002, 1, 41-48.

5. Brannen, K.C.; Panzica-Kelly, J.M.; Danberry, T.L.; Augustine-Rauch, K.A. Development of a zebrafish embryo teratogenicity assay and quantitative prediction model. Birth Defects Res. B 2010, 89, 66-77. 
6. Shao, C.L.; Wu, H.X.; Wang, C.Y.; Liu, Q.A.; Xu, Y.; Wei, M.Y.; Qian, P.Y.; Gu, Y.C.; Zheng, C.J.; She, Z.G.; et al. Potent antifouling resorcylic acid lactones from the gorgonian-derived fungus Cochliobolus lunatus. J. Nat. Prod. 2011, 74, 629-633.

7. Shao, C.L.; Wang, C.Y.; Wei, M.Y.; Gu, Y.C.; She, Z.G.; Qian, P.Y.; Lin, Y.C. Aspergilones A and $\mathrm{B}$, two benzylazaphilones with an unprecedented carbon skeleton from the gorgonian-derived fungus Aspergillus sp. Bioorg. Med. Chem. Lett. 2011, 21, 690-693.

8. Zheng, C.J.; Shao, C.L.; Guo, Z.Y.; Chen, J.F.; Deng, D.S.; Yang, K.L.; Chen, Y.Y.; Fu, X.M.; She, Z.G.; Lin, Y.C.; et al. Bioactive hydroanthraquinones and anthraquinone dimers from a soft coral-derived Alternaria sp. fungus. J. Nat. Prod. 2012, 75, 189-197.

9. Yang, K.L.; Wei, M.Y.; Shao, C.L.; Fu, X.M.; Guo, Z.Y.; Xu, R.F.; Zheng, C.J.; She, Z.G.; Lin, Y.C.; Wang, C.Y. Antibacterial anthraquinone derivatives from a sea anemone-derived fungus Nigrospora sp. J. Nat. Prod. 2012, 75, 935-941.

10. Li, E.; Jiang, L.; Guo, L.; Zhang, H.; Che, Y. Pestalachlorides A-C, antifungal metabolites from the plant endophytic fungus Pestalotiopsis adusta. Bioorg. Med. Chem. 2008, 16, 7894-7899.

11. Wen, L.; Cai, X.; Xu, F.; She, Z.; Chan, W.L.; Vrijmoed, L.L.; Jones, E.B.; Lin, Y. Three metabolites from the mangrove endophytic fungus Sporothrix sp. (\#4335) from the South China Sea. J. Org. Chem. 2009, 74, 1093-1098.

12. Umeyama, A.; Ito, S.; Yuasa, E.; Arihara, S.; Yamada, T. A new bromopyrrole alkaloid and the optical resolution of the racemate from the marine sponge Homaxinella sp. J. Nat. Prod. 1998, 61, 1433-1434.

13. Gao, Y.; Wang, G.-Q.; Wei, K.; Hai, P.; Wang, F.; Liu, J.-K. Isolation and biomimetic synthesis of $( \pm)$-Guajadial B, a novel meroterpenoid from Psidium guajava. Org. Lett. 2012, 14, 5936-5939.

14. Pierce, C.G.; Uppuluri, P.; Teistan, A.R.; Wormley, J.F.L.; Mowat, E.; Ramage, G.; Lopez-ribot, J.L. A simple and reproducible 96-well plate-based method for the formation of fungal biofilms and its application to antifungal susceptibility testing. Nat. Protoc. 2008, 3, 1494-1500.

15. Yu, Y.-M.; Yang, J.-S.; Peng, C.-Z.; Caer, V.; Cong, P.-Z.; Zou, Z.-M.; Lu, Y.; Yang, S.-Y.; Gu, Y.-C. Lactones from Angiopteris caudatiformis. J. Nat. Prod. 2009, 72, 921-924.

(C) 2013 by the authors; licensee MDPI, Basel, Switzerland. This article is an open access article distributed under the terms and conditions of the Creative Commons Attribution license (http://creativecommons.org/licenses/by/3.0/). 